\title{
The Evolution of the Journal Club: From Osler to Twitter
}

Joel M. Topf MD¹, Matthew A. Sparks MD², Paul J. Phelan MD³, Nikhil Shah MBBS

DNB ${ }^{4}$, Edgar V. Lerma MD ${ }^{5}$, Matthew P.M. Graham-Brown MD MRes ${ }^{6}$, Hector Madariaga $\mathrm{MD}^{7}$, Francesco lannuzzella $\mathrm{MD}^{8}$, Michelle N. Rheault $\mathrm{MD}^{9}$, Thomas Oates MD $\mathrm{PhD}^{10}$, Kenar D. Jhaveri MD ${ }^{11}$, Swapnil Hiremath MD MPH ${ }^{12}$

${ }^{1}$ Oakland University William Beaumont School of Medicine, Detroit, MI

${ }^{2}$ Division of Nephrology, Department of Medicine, Duke University and Durham VA Medical Center, Durham, NC

${ }^{3}$ Department of Nephrology, Royal Infirmary of Edinburgh, NHS Lothian, UK ${ }^{4}$ Dept of Nephrology and Immunology, University of Alberta, Edmonton, Canada ${ }^{5}$ University of Illinois at Chicago/ Advocate Christ Medical Center, Oaklawn, IL ${ }^{6}$ John Walls Renal Unit, University Hospital Leicester NHS Trust, Leicester, UK ${ }^{7}$ University of Maryland Medical Center, Division of Nephrology, Baltimore, MD ${ }^{8}$ Nephrology and Dialysis Unit, Arcispedale Santa Maria Nuova, Reggio Emilia, Italy ${ }^{9}$ Department of Pediatrics, University of Minnesota Masonic Children's Hospital ${ }^{10}$ UCL Centre for Nephrology, London, UK 
Topf et al The Online NephJC

${ }^{11}$ Hofstra Northwell School of Medicine, Hempstead NY Division of Kidney Diseases

and Hypertension, Department of Medicine, North Shore University Hospital and Long Island Jewish Medical Center, Northwell Health, Great Neck, NY

${ }^{12}$ University of Ottawa and Ottawa Hospital Research Institute, Ottawa, Canada

Figures 2

Tables 4

Word count 3571 (including abstract)

Keywords: Journal Club, Social Media, Education, Twitter, Medical, Nephrology

Corresponding Author:

Swapnil Hiremath

1967 Riverside drive

Ottawa, ON

Canada K1H7W9

Tel: 16137388400 ext 82762 Fax: 16137388337

Email: shiremath@toh.ca

\section{Funding Information :}

MAS is funded by Career Development Award IK2BX002240 from the Department of Veterans Affairs, Office of Research and Development, Biomedical Laboratory 
Topf et al The Online NephJC

Research and Development Service. SH receives research salary support from the

Faculty of Medicine, University of Ottawa. There was no specific funding available for this project or this manuscript.

\section{Disclosures:}

None of the authors have any relevant competing interests to declare

\section{Acknowledgements:}

We would like to thank the other members of the NephJC team, Graham Abra, Suzanne Norby and Scherly Leon, as well all the NephJC participants 


\section{Abstract}

Journal clubs typically have been held within the walls of academic institutions, and in medicine have served the dual purpose of helping foster critical appraisal of literature and disseminate new findings. In the last decade, and especially the last few years, online and virtual journal clubs have been started and are flourishing, especially those harnessing the advantages of social media tools and customs. This article reviews the history and recent innovations of journal clubs. In addition, the authors describe their experience developing and deploying an online nephrology journal club based on twitter, NephJC.

Keywords: journal club; twitter; medical education; social media 


\section{Introduction}

Journal clubs are widely used in medical education in part because they are so versatile. They aid in teaching the systematic evaluation and interpretation of the published literature and are a means to share the latest advances in medicine. The journal club is approaching 200 years of age, however, it continues to evolve to solve new problems and employ new technologies ${ }^{1-3}$. The latest example of this is journal clubs using social media to discuss and debate the published literature. Numerous journal clubs meet virtually to discuss new and high impact articles with participants from around the world. One such online journal club, Nephrology Journal Club (NephJC), meets twice a month to discuss the contemporary nephrology literature. This article reviews the history and scholarly research performed on journal clubs, describes the characteristics of modern, online journal clubs, and provides data from the NephJC experience.

\section{The History of Journal Clubs}

The first use of the term "journal club" is in the memoirs and letters of James Paget. Dr Paget described a lounge outside of St Bartholomew's Hospital in London from 18351854 where physicians socialized and read journals ${ }^{1}$. However, it is William Osler who is credited with creating the modern journal club while at McGill University, Montreal in 1875. Osler encouraged collective reading of subscription journals in order to spread the prohibitively high cost of print periodicals ${ }^{1}$. The McGill journal club model was widely imitated. Johns Hopkins held its first journal club in 1889, and by the first few decades of the twentieth century most departments in Hopkins were hosting their own monthly 
journal clubs. These specialty specific journal clubs were typically held in the homes of participating physicians ${ }^{4}$. Tinsley Harrison (creator of Harrison's Principles of Internal Medicine) used to host a journal club at his house twice a month, at which one participant would present a paper and the assembled audience would critique ${ }^{5}$.

Mattingly reported the first peer-reviewed paper primarily about journal clubs in $1966^{6}$. He described the popularity of journal clubs "in the United States, where they are a regular and often compulsory feature of hospital life." ${ }^{6}$ By the 1980s, a survey of internal medicine residency programs in New York demonstrated that 85\% included a journal club $^{7}$. Mattingly defined a journal club as "a group of doctors meeting regularly to discuss papers of interest in the current medical journals." ${ }^{6} \mathrm{He}$ added that though different members of the club have different goals, "The essential feature of any journal club, however, is that all the members should present papers at one time or another and take part in the subsequent discussions." ${ }^{6}$ The key was an engaged rather than passive audience ${ }^{6}$. Mattingly thought that having an engaged interactive discussion put restrictions on the size of the journal club. Too many people and not everyone can participate; too few, and there is insufficient dialog to generate fulfilling two-way interactions. He thought that journal clubs should have no fewer than six participants and no more than twelve. A recurring theme in narrative descriptions of various journal clubs is practices that reduce formalities in order to make the environment more casual. These include hosting the event outside the hospital campus and adding food and drinks to the event ${ }^{89}$. Since journal clubs are one of the few examples in traditional medical education with peer-to-peer teaching, steps that enhance informality could 
Topf et al The Online NephJC

potentially stimulate interaction. Leaving the hospital grounds may serve to deemphasize the normal educational hierarchy. This characteristic was in play in the very first journal club, which was held outside of the St Bartholomew's Hospital ${ }^{1}$. Recent work has suggested that this informality adds to the acceptance of the journal club itself 8.

The journal club has evolved to serve various medical education needs. For example, the journal club has been adopted to teach the fundamentals of critically appraising the literature ${ }^{10} 11$. Riegelman encouraged the use of a structured format when presenting articles. This is described by the Method, Assignment, Assessment, Results, Interpretation, Extrapolation frameworks (MAARIE framework) ${ }^{12}$. Gehlbach, et al. promoted the use of a formal 8 week evidence based medicine (EBM) curricula conducted in parallel with a journal club ${ }^{13}$. Linzer tested the ability of a journal club to improve EBM education in a randomized controlled trial, and reported that a journal club-based curriculum was better than a weekly, faculty administered lecture at teaching the principles of EBM ${ }^{14}$. Deenadayalan et al. performed a systematic review of the literature on journal clubs and found 12 studies that objectively attempted to characterize and measure the effectiveness of journal clubs. They used this data to establish a set of best practices for journal clubs ${ }^{15}$ (See box 1). Similarly, another systematic review, including 16 studies, reported an improvement in reading habits and critical appraisal skills in the attendees ${ }^{16}$. 
Topf et al The Online NephJC

\section{From the classroom to the laptop}

A number of factors contributed to the journal club transitioning from face-to-face interaction to online interaction:

1. The conversational nature of journal clubs allowed for the incorporation of existing online platforms such as Twitter, which were designed for conversational interaction, to facilitate rapid, real-time, dialog between learners.

2. Online tools allowed for learners from different locations to join in a virtual round table discussion. This is important for physicians who have graduated training and are no longer in academic medical centers.

3. Online journal clubs allow a variety of physicians, ancillary providers, patient advocates, authors, and content experts to participate.

4. An online presence allows flexibility in the time of the event.

The online journal club has gone through a number of iterations. Early online journal clubs were lacking the important interactive quality. Kidney International (KI) was among the first to form an online journal club, and it is still in use today. It consists of a series of expert summaries of selected articles from other journals ${ }^{17}$. The summaries are written by experts in the field, and contextualize the article by discussing prior research. The summary addresses controversies in the study design. Lastly, the article specifies what this study adds to the established literature. Though these essays are called 'journal clubs' they lack any two-way interactive discussion. A journal club dedicated to pediatric 
infectious disease followed a similar model, with consultants submitting a critical appraisal to the pediatric special interest group of the Australian Society of Infectious Diseases who posted it on a dedicated website. This model was popular and the organizers found a 6 -fold increase in web traffic with the journal club ${ }^{18}$. However, like $\mathrm{KI}$, the lack of a two-way information exchange makes this more of a literature appraisal and less an interactive journal club.

The Clinical Journal of the American Society of Nephrology (CJASN) started an online, monthly journal club in September of 2011 called the CJASN eJournal Club (eJC) ${ }^{19}$. The CJASN eJC model included an initial critical appraisal of a selected article, in the form of a text summary or a slide presentation. This was prepared by a rotating group of individuals from various nephrology divisions. The actual discussion then occurred in a forum, with questions and replies threaded together. Authors were encouraged to participate and reply to questions. CJASN made the article and its associated editorial available to anyone with a free eJC account (no subscription to CJASN was necessary). The CJASN eJC covered 48 articles and generated 434 comments over 4 years. Though the articles that were made free were widely downloaded, the interactive forum didn't attract a dedicated or enthusiastic following. Many article had no comments at all. The journal club's last article was December 2015. (D. Goldfarb, Personal communication, April 4, 2016) 
Another approach to an online journal club is the Wiki Journal club (WJC), which leverages the software that underlies Wikipedia to build an encyclopedia of high impact clinical trials. WJC contributors collectively write summaries and critical appraisals of important trials. What differentiates this from the $\mathrm{KI}$ journal club or the Australian Society of Infectious Diseases' effort is that the process is open to any interested participant and what ultimately gets published comes after a considered time of discussion. As of April 2015 WJC had reviewed 284 articles, 31 focused on nephrology, making WJC the most prolific online journal club in terms of volume ${ }^{20}$.

Though the use of online journal clubs has a checkered history, there is one domain in which they are flourishing, Twitter. Twitter is a open online publishing platform where users can post text, images, and links in small 140 character posts. The posts are broadcast to anyone who chooses to follow the user. The twitter 'handle' refers to a user account and begins with an '@' symbol (eg @NephJC is the handle of the nephrology journal club). A hashtag (or pound) symbol '\#' followed by a string (eg \#NephJC), serves as a label or metadata tag to help users find messages with a particular theme. The first medical journal club with any connection to Twitter, was conducted on December 11 , 2008 by Dr. Ves Dimov. In this instance Twitter was used to publish notes and comments from a live, in-person, journal club at Creighton University's Division of Allergy and Immunology 21 . This was the first documented use of Twitter in a journal club, but it may be more accurately described as using Twitter to extend a face-to-face journal club beyond the institution. The first journal club to use Twitter as the primary 
means of interaction was in 2011 when Drs. Natalie Silvey and Fi Douglas started The Twitter Journal Club ${ }^{22}$. It was a general internal medicine journal club and it established a number of precedents for subsequent Twitter journal clubs. A week or so prior to the journal club, the organizers posted a summary of the article on a dedicated website. In order to be part of the conversation, each tweet needed to include the hashtag \#TwitJC. Searching for the hashtag allowed participants to read everyone's comment on the discussion, whether one followed that individual or not. This hashtag system had previously been used for discussions around a topic. The Twitter Journal Club simply exploited an existing feature, in an existing social network, to achieve a workable facsimile of a face-to-face journal club. Following the discussion, the organizers posted a summary of the discussion to the journal club's website. Following the success of Twitter Journal Club a number of other specialty specific journal clubs have emerged (table 1). Roberts et al. did a systematic review of Twitter journal clubs. Of the 24 Twitter journal clubs analyzed, NephJC had the highest number of tweets and the greatest impressions per month, a reflection of the reach of the journal club (impressions is number of tweets multiplied by number of followers of the tweet author $)^{23}$.

\section{The NephJC Experience}

The authors of this article are the principal organizers of the online nephrology journal club, NephJC. All of the interactive discussions occur on Twitter. Over the past two and a half years NephJC has evolved various practices to encourage attendance and interaction with the journal club. In the following section, we describe data on 
Topf et al The Online NephJC

participation obtained from Symplur, which is a service that collects and makes

available data on participation rate and tweet statistics for any registered hashtag ${ }^{24}$.

\section{Participation in NephJC journal club tweetchats}

Since the inception of NephJC (April 2014), 61 journal club discussions have been conducted (throughNovember $2^{\text {nd }} 2016$ ). NephJC primarily reviews original clinical research but has committed to a wider scope to better reflect the diversity of documents that guide the field of nephrology forwards (see table 2 for details).

During this period, over 2,500 unique twitter handles have used the \#NephJC hashtag in 40,802 tweets ${ }^{24}$. The median number of participants in a NephJC journal club is 61.6 interquartile range, IQR, 41, 78). Given the open nature of the tweetchat, the typical active chat participant is commonly a practicing nephrologist, but also includes residents and trainees, physicians from other specialties, other interested healthcare providers, and patients. The median number of individual tweets at a particular NephJC session is 577 (IQR 382.5, 696.5). Additional data about chat participation grouped according to key select characteristics are presented in tables 3 and 4 . Non-traditional topics for a journal club, such as discussing a review paper, a clinical practice guideline or a book club, also has been well received in terms of participation.

\section{The NephJC model}

The cycle of events that mark each NephJC can be divided into 8 steps:

1. Selecting an article

2. Summary of the article at NephJC.com 
3. Invite content experts and authors. Correspond with the journal editors to request the article be made open access, if not already

4. Email newsletter

5. Chat one on Tuesday for the Americas at 9 PM Eastern Standard Time

6. Chat two on Wednesday for Africa and Europe at 8 PM Greenwich Mean Time

7. Publish an archive and a curated archive of the best tweets

8. Summary of the chats published to PubMed Commons

\section{The selection committee}

NephJC is conducted twice a month and has a work group that select the articles, consisting of fifteen nephrologists (including one pediatric nephrologist) from five countries. The work group selects high impact and controversial articles, primarily in clinical nephrology, based on expert consensus. Other discussions are special events as detailed in table 3. Some articles have been selected by using online opinion polls, by providing a short list to choose from. Relevant articles are selected not just from core nephrology journals, but general medical and other specialty journals as well, and the latter are associated with higher participation (see table 4). .

\section{The summary}

A week before each Tweet chat a summary of the article is published to the NephJC website $^{25}$. These summaries usually run 800 to 1,200 words. In addition to summarizing the article, these posts detail the background of the study to put it in context and raise possible areas of discussion. These summaries also act as 'homepages' for the chats. This homepage is used to post future updates such as further background posts, editorials, archives, curated summaries, and reports on the participation in the chat. 
Discussions that occur only in Twitter are fleeting and difficult to find in the future. The web presence anchors the discussion so that it can be indexed and more easily found for future reference.

\section{Email newsletter}

NephJC has a weekly email that is delivered to individuals that have requested it.

Currently the e-mail is sent to 671 email accounts once a week. The email promotes the upcoming journal clubs, summarizes the previous chats and publicizes other nephrology events.

\section{Invitation}

Content experts and/or authors are invited to join the discussion. The presence of a content expert makes the journal club a richer educational experience. People with deep familiarity with the area under question often make better observations, have greater insights into the mechanisms and pathophysiology, and stimulate a higher level of discussion. Authors join in just over one third of the chats ${ }^{26}$. The presence of an author is associated with numerically higher participation rates and greater number of tweets (see table 4).

\section{Chat 1}

The chat is the central activity of the journal club. NephJC is a synchronous chat where people meet to discuss the article at one time. This allows a real-time back and forth conversation much more like a face-to-face meeting. In contrast, several other journal clubs do asynchronous chats where people are instructed to discuss an article over a multi-day period. An example of this is the Urology Journal Club (@IUJC, \#urojc). Their 
discussion begins on Sunday and runs until Wednesday of the same week ${ }^{27}$. The synchronous model of NephJC generates more tweets per participant but can exclude people from time zones that do not line up with a convenient time. The NephJC chat itself lasts one hour.

\section{Chat 2}

For the first 8 months of NephJC a single chat per article was the norm. However, the timing of this chat, $9 \mathrm{pm}$ Eastern, corresponds to $2 \mathrm{am}$ in London. This inconvenient time for people in Europe stimulated demand for a second NephJC chat to better serve Africa and Europe. This chat runs Wednesdays at 8 pm(Greenwich Mean Time). Conveniently, this corresponds to noon on the west coast of the US and some individuals participate from there. The addition of the second chat has increased individual participation rates (see table 4).

\section{Archives}

After the chat, two archives of the proceedings are made available on the NephJC website. One is an archive of every tweet that incorporates the tag \#NephJC. This archive is produced by Symplur (http://www.symplur.com), a company that provides Twitter analytics and tracks health-related hashtags. The second archive is a curated archive that includes selected tweets, along with some article links, pictures and other important information. The curation allows the tweets to be reordered so it is easier to read through them. Related conversations are kept together and low value tweets are dropped. The curated digest is created with a free, online tool, called Storify, and is posted on the NephJC website as well as being available on the NephJC Storify website $^{28}$ 


\section{PubMed Commons}

The National Library of Medicine (NLM) started PubMed Commons in December 2013 (The NCBI Staff, 2013). This allows any individual who has authored an article indexed in PubMed to non-anonymously comment on any article. A major impetus for PubMed Commons is promoting and documenting post publication peer review ${ }^{29}$. Recognizing that journal clubs are a form of post-publication peer review, the NLM has provided commenting privileges to NephJC, among other online journal clubs ${ }^{30} 31$. The NephJC work group composes a short summary of the NephJC discussion with links to the full and curated archives for all of the Tweet Chats and posts them as comments on the articles' listing in the index. This is similar to links to letters about the article that are found on the parent article listing.

The eight steps highlighted above are repeated twice a month and form the core of NephJC. There are other ways to organize a Twitter journal club but the choices the NephJC work group made were intended to help build a robust, academically-minded, nephrology community on Twitter. To this goal, both the newsletter and the website are particularly important. The newsletter extends the reach of NephJC beyond people already engaged with social media. The website provides permanence in a social media world that is defined by a short shelf-life. Moreover, the NephJC website provides a location for people to reference the chat in the future. For example, in the comments on PubMed Commons, NephJC links to the website rather than individual tweets. Another factor in the success of NephJC is the large number of people on the Work Group. Many online journal clubs have had a short lifespan (see table 1). For example, the 
original twitter journal club innovator, TwitJC, is no longer active. The NephJC work group has 15 people and is growing to keep the workload sustainable..

\section{Challenges}

As can be seen above, the coordination and execution of an journal club requires a fair amount of work. Therefore, it is not surprising to note the attrition rate of active online journal clubs (see table 1 for examples). Additionally, the timing of the live chat, usually in the evening after work hours, may make it more convenient for some, but may intrude on family time for others. Most importantly, this form of a journal club is primarily useful for those who already using social media. Advantages of social media based journal clubs is that they allow individuals outside academia and formal training programs to connect and learn. Social media based medical education may have an important role in meeting needs of ongoing lifelong learning. NephJC has explored offering continued medical education (CME) credits. However this may require funding and would increase the workload, particularly if the CME needed to be offered for multiple countries.

\section{Conclusions}

There are many advantages to an online journal club that can facilitate ongoing medical education by allowing participants to be exposed to opinions from outside of their own practice environment. In addition, online journal clubs allow for participation by experts in the topic at hand, frequently including author participation, to provide insight into the article discussed that may not have otherwise been apparent. The informal nature of social media pairs well with a journal club that thrives in an informal environment. It is more than just a coincidence that journal clubs have thrived on social media compared to other online systems. 
Topf et al The Online NephJC

The journal club is approaching 200 years of age. It is a durable component of medical education because it has been able to adapt to serve different purposes and use different technologies. Today the journal club is adapting to social media with some success. By freeing the journal club from the academic teaching center, the online journal club can be used by doctors after graduation to keep abreast of medical advancements. 


\section{Figure legends}

Figure 1: Examples of the back and forth conversation that drives the journal club. 1a A. Moderator/Host introducing the methods. B. Point raised about weakness in methodology. C. Reply from moderator, and inviting comment from author, Perry Wilson. D and E. Clarification from author

1b A. Participant calculating number needed to harm $(\mathrm{NNH})$, and tweeting picture to show calculation. B. Clarification from moderator about correct calculation. C. Comment from author, arguing NNH redundant since medicine (in this case proton pump inhibitors) perhaps of no benefit. Smiley indicates this was made in jest. D. Reply to refute the authors assertion. E. Moderator asks for reference to back up the assertion above. F. Citation provided in response.

Figure 2: Graphical representation of tweets and participation in NephJC till Nov 2 2016. Line refers to number of participants (axis label on right side). Bar graph refers to participants: overall with subgroups based on color. The typewriter symbol refers to chats where there was author participation. The additional European chat started with chat labelled 'Rituximab ANCA'. 
Box 1: Characteristics of a sustainable and effective journal club (from

Deendayalan et al, used with permission)

Journal club attendance

- Establish a journal club group of members of the same discipline, or similar interests within a clinical specialty.

Journal club purpose

- Have an established and agreed overarching goal for the long term journal club intervention. The overarching journal club purpose should be reviewed regularly, and agreed by participants

- Establish the purpose of each journal club meeting, and link this to the paper being read, or the skill acquisition being addressed.

Structure of an effective journal club

- Regular attendance should be expected and recorded. Attendance may be mandatory, particularly if the journal club has a curriculum-based format

- Conduct journal clubs at regular predictable intervals (suggest monthly)

- Conduct journal club at an appropriate times of the day for all participants

- Provide incentives to attend such as food (which is shown to increase attendance as well as the conviviality of the occasion). 
Leading journal club

- Journal clubs appear to be more effective if they have a leader. The journal club leader should be responsible for identifying relevant articles for discussion, however the final choice needs to be decided by the journal club members

- Train the leader/facilitator of the journal club in relevant research design and/or statistical knowledge so as to appropriately direct group discussions and assist the group to work towards its goals

- The leader can change from meeting to meeting, however he/she needs to have the skills to present the paper under discussion and lead the group adequately. It is a fine balance between choosing a leader of high academic standing whose expertise may stifle discussion, or choosing a leader from peers who may not have the requisite understanding of the paper under discussion

- Provide access to a statistician to assist the leader in preparing for journal club, and to answer questions that may arise from the journal club discussion

Choosing articles for discussion

- Choose relevant case-based or clinical articles for discussion. These papers should be of interest to all participants. Articles should be chosen in line with the overarching purpose of the journal club

- Identify one journal club member (either the designated leader or a member) 
who has the responsibility for identifying the literature to be discussed for each meeting. This person should also lead the discussion on the article at the journal club.

Circulating articles for discussion

- Provide all participants for each journal club (in addition to the leader) with prereading at a suitable time period prior to the journal club (may be up to a week prior). Participants should agree to the time frame for pre-reading. In some curriculum-based situations, assessment of whether pre-reading has occurred may be appropriate

- Use the internet as a means of distributing articles prior to the meeting, maintaining journal club resources and optimizing use of time and resources.

Efficiently running the journal club

- Use established critical appraisal approaches and structured worksheets during the journal club session, which leads to healthy and productive discussion

- Formally conclude each journal club by putting the article in context of clinical practice.

Journal club effectiveness

- Depending on the journal club purpose, it may be appropriate to evaluate knowledge uptake formally or informally 
Topf et al The Online NephJC

- Evaluation should specifically relate to the article(s) for discussion, critical appraisal, understanding of biostatistics reported in the paper and translating evidence into practice. 
Topf et al The Online NephJC

Table 1: A list of online, twitter-based medical journal clubs

\begin{tabular}{|c|c|c|c|c|}
\hline Name & Date started & Twitter ID & Hashtag & $\begin{array}{l}\text { Active/ } \\
\text { Inactive } \\
\text { (mm/yy) }\end{array}$ \\
\hline Twitter Journal Club & May 2011 & @twitjournalclub & \#twitjc & $\begin{array}{l}\text { Inactive } \\
(12 / 13)\end{array}$ \\
\hline $\begin{array}{l}\text { Public Health Twitter } \\
\text { Journal Club }\end{array}$ & August 2011 & $@$ PHTwitJC & \#PHTwitJC & $\begin{array}{l}\text { Inactive } \\
(8 / 13)\end{array}$ \\
\hline $\begin{array}{l}\text { British Journal of } \\
\text { Obstetrics and } \\
\text { Gynaecology Journal } \\
\text { Club }\end{array}$ & May 2012 & $@$ BlueJCHost & \#bluejc & Active \\
\hline $\begin{array}{l}\text { Microbiology Twitter } \\
\text { Journal Club }\end{array}$ & May 2012 & $@$ @microtwjc & \#microtwjc & $\begin{array}{l}\text { Inactive } \\
(1 / 16)\end{array}$ \\
\hline St Emyn's Journal Club & October 2012 & @JC_StE & \#JC_StE & $\begin{array}{l}\text { Inactive } \\
(9 / 14)\end{array}$ \\
\hline Urology Journal Club & $\begin{array}{l}\text { November } \\
2012\end{array}$ & @iurojc & \#urojc & Active \\
\hline Evidence Based Nursing & January 2013 & $@ E B N u r s i n g B M J$ & \#ebnjc & Active \\
\hline
\end{tabular}


Topf et al The Online NephJC

\begin{tabular}{|c|c|c|c|c|}
\hline Twitter Journal Club & & & & \\
\hline $\begin{array}{l}\text { Hospice and Palliative } \\
\text { Care medicine }\end{array}$ & $\begin{array}{l}\text { February } \\
2013\end{array}$ & $@$ @pmjc & \#hpmjc & Active \\
\hline $\begin{array}{l}\text { Respiratory and Sleep } \\
\text { Medicine Journal Club }\end{array}$ & October 2013 & @respandsleepjc & $\#$ \#sjc & Active \\
\hline $\begin{array}{l}\text { Academic Life in } \\
\text { Emergency Medicine } \\
\text { Journal Club }\end{array}$ & $\begin{array}{l}\text { November } \\
2013\end{array}$ & $@ M \_$Lin & \#ALIEMJC & $\begin{array}{l}\text { Inactive } \\
(3 / 15)\end{array}$ \\
\hline $\begin{array}{l}\text { General Surgery Journal } \\
\text { Club }\end{array}$ & $\begin{array}{l}\text { February } \\
2014\end{array}$ & @igsjc & \#igsjc & $\begin{array}{l}\text { Inactive } \\
(2 / 16)\end{array}$ \\
\hline $\begin{array}{l}\text { Primary Care Medicine } \\
\text { Journal Club }\end{array}$ & $\begin{array}{l}\text { February } \\
2014\end{array}$ & $@ p c m j c$ & $\# p c m j c$ & $\begin{array}{l}\text { Inactive } \\
(3 / 14)\end{array}$ \\
\hline Allergy Journal Club & March 2014 & @allergyjc & \#allergyjc & $\begin{array}{l}\text { Inactive } \\
(3 / 14)\end{array}$ \\
\hline Nephrology Journal Club & April 2014 & @nephjc & \#nephjc & Active \\
\hline Radiation Oncology & August 2014 & @rad_nation & \#radonc & Active \\
\hline $\begin{array}{l}\text { Geriatric Medicine } \\
\text { Journal Club }\end{array}$ & August 2014 & $@$ @eriMedJC & \#GeriMedJC & Active \\
\hline $\begin{array}{l}\text { International Psychiatric } \\
\text { Journal Club }\end{array}$ & $\begin{array}{l}\text { December } \\
2014\end{array}$ & $@$ PsychiatryJC & \#PsychJC & $\begin{array}{l}\text { Inactive } \\
(6 / 15)\end{array}$ \\
\hline $\begin{array}{l}\text { Duke Anesthesiology } \\
\text { Journal Club }\end{array}$ & January 2015 & @Duke_Anesthesi & \#AnesJC & Active \\
\hline
\end{tabular}


Topf et al The Online NephJC

\begin{tabular}{|c|c|c|c|c|}
\hline $\begin{array}{l}\text { Rheumatology Journal } \\
\text { Club }\end{array}$ & $\begin{array}{l}\text { February } \\
2015\end{array}$ & $@$ RheumJC & \#RheumJC & Active \\
\hline $\begin{array}{l}\text { Amyloidosis Journal } \\
\text { Club }\end{array}$ & October 2015 & @Amyloid_Planet & \#amyloidosisJ & Inactive \\
\hline $\begin{array}{l}\text { GIM Journal Club } \\
\text { (General Internal } \\
\text { Medicine) }\end{array}$ & $\begin{array}{l}\text { December } \\
2015\end{array}$ & $@$ GIMJClub & \#GenMedJC & Active \\
\hline $\begin{array}{l}\text { General Practice Journal } \\
\text { Club }\end{array}$ & January 2016 & $@$ GPjournalclub & \#GPJC & Active \\
\hline Pathology Journal Club & June 2016 & @Path_JC & \#PathJC & Active \\
\hline $\begin{array}{l}\text { Family Medicine Online } \\
\text { Journal Club }\end{array}$ & August 2016 & @familymedjc & \#familymedjc & Active \\
\hline $\begin{array}{l}\text { International Pediatric } \\
\text { Nephrology Journal Club }\end{array}$ & $\begin{array}{l}\text { November } \\
2016\end{array}$ & @IPNA_PedNeph & \#IPNAJJC & Active \\
\hline
\end{tabular}

Source: Wikipedia article on twitter based journal clubs ${ }^{32}$ Last date of activity verified with hashtag on twitter on Nov 10 2016. Inactive journal clubs have last month of activity presented in parenthesis in month/year format 
Topf et al The Online NephJC

Table 2: Types of articles featured in NephJC discussions

\begin{tabular}{|c|c|c|}
\hline Article types & Features & Examples \\
\hline Original Clinical Research & $\begin{array}{l}\text { Standard, most common } \\
\text { version }\end{array}$ & $\begin{array}{l}\text { Clinical research - trials, } \\
\text { observational studies, } \\
\text { meta-analyses }\end{array}$ \\
\hline Biomedical Research & $\begin{array}{l}\text { Greater discussion of } \\
\text { methods, author } \\
\text { participation more common }\end{array}$ & $\begin{array}{l}\text { Animal models of human } \\
\text { disease }\end{array}$ \\
\hline Book Club & $\begin{array}{l}\text { Multiple blog posts } \\
\text { summarizing each chapter } \\
\text { leading up to a Tweet Chat } \\
\text { about the book }\end{array}$ & $\begin{array}{l}\text { 'Being Mortal' by Atul } \\
\text { Gawande 'The Patient Will } \\
\text { See You Now' by Eric } \\
\text { Topol }\end{array}$ \\
\hline Guidelines and Reviews & $\begin{array}{l}\text { These serve to discuss the } \\
\text { strengths and weaknesses } \\
\text { of a particular guideline, } \\
\text { and also as knowledge } \\
\text { translation - to make users } \\
\text { aware and understand } \\
\text { new guidelines }\end{array}$ & $\begin{array}{l}\text { ACP Nephrolithiasis } \\
\text { Guidelines; European } \\
\text { Hyponatremia Guidelines, } \\
\text { Extracorporeal Treatment } \\
\text { In Poisoning (EXTRIP) } \\
\text { guidelines }\end{array}$ \\
\hline Special Chats & Built around a special & DreamRCT, NephJC live, \\
\hline
\end{tabular}


Topf et al The Online NephJC

\begin{tabular}{|l|l|l|}
\hline educational event (eg & Social Media in Medicine \\
KidneyWk 2014 and & (Chisholm, 2015) \\
NephJC Live; the & DreamRCT initiative to \\
promote new trial ideas in & \\
Nephrology $)$ & \\
\hline
\end{tabular}


Table 3: Details of NephJC journal club participation according to type of article being discussed

\begin{tabular}{|l|l|l|l|}
\hline Type of Article & N & $\begin{array}{l}\text { Participants } \\
\text { (median, } \\
\text { interquartile } \\
\text { range) }\end{array}$ & $\begin{array}{l}\text { Tweets(median, } \\
\text { interquartile } \\
\text { range) }\end{array}$ \\
\hline All & 61 & $58(41,78)$, & $577(382.5$, \\
Research & 47 & $58(43,79)$ & $696.5)$ \\
\hline Original Clinical & $377(398,717)$ \\
\hline Research & 3 & $53(38,60)$ & $453(276,677)$ \\
\hline Book Club & 2 & $52.5(44,61)$ & $454.5(445,464)$ \\
\hline Guidelines & 3 & $73(38,148)$ & $686(340,1090)$ \\
\hline Reviews & 3 & $39(26,72)$ & $641(213,684)$ \\
\hline Special Chats & 3 & $65(44,126)$ & $660(252,1005)$ \\
\hline
\end{tabular}


Table 4: Details about participation at NephJC journal club twitter chats based on certain key characteristics

\begin{tabular}{|l|l|l|l|}
\hline Characteristics & $\mathbf{N}$ & $\begin{array}{l}\text { Participants(median, } \\
\text { interquartile range) }\end{array}$ & $\begin{array}{l}\text { Tweets(median, } \\
\text { interquartile range) }\end{array}$ \\
\hline $\begin{array}{l}\text { American chat } \\
\text { alone }\end{array}$ & 17 & $32(24,41.5)$ & $270(235.5,333.5)$ \\
\hline $\begin{array}{l}\text { American + EU } \\
\text { chats }\end{array}$ & 44 & $65(50.5,83.25)$ & $641(532.75,726.5)$ \\
\hline Presence of & 25 & $65(50,80)$ & \\
Author & 36 & $50(38,75)$ & $641(517,714.5)$ \\
\hline Absence of & & & $466.5(281.75,655.5)$ \\
\hline Author & 40 & $54(40,75.75)$ & $591(374.75,672.75)$ \\
\hline $\begin{array}{l}\text { Core } \\
\text { Nephrology } \\
\text { other specialties }\end{array}$ & 21 & $65(41.5,80)$ & \\
\hline Involvement of & & & \\
\hline
\end{tabular}




\begin{tabular}{|l|l|l|l|}
\hline $\begin{array}{l}\text { General Medical } \\
\text { Journals }\end{array}$ & 29 & $58(41,78)$ & $565(362.5,719)$ \\
\hline $\begin{array}{l}\text { Nephrology } \\
\text { Journals }\end{array}$ & 20 & $50(38.25,94.25)$ & $591(346.75,655.25)$ \\
\hline $\begin{array}{l}\text { Other specialty } \\
\text { journals }\end{array}$ & 8 & $64(54.75,80.75)$ & $692(500.25,726.5)$ \\
\hline
\end{tabular}

\section{References}

1. Linzer M. The journal club and medical education: over one hundred years of unrecorded history. Postgrad Med J 1987;63(740):475-8.

2. Palan J, Roberts V, Bloch B, Kulkarni A, Bhowal B, Dias J. The use of a virtual learning environment in promoting virtual journal clubs and case-based discussions in trauma and orthopaedic postgraduate medical education: the Leicester experience. J Bone Joint Surg Br 2012;94(9):1170-5.

3. Sortedahl C. Effect of online journal club on evidence-based practice knowledge, intent, and utilization in school nurses. Worldviews Evid Based Nurs 2012;9(2):117-25.

4. Chesney AM. The contribution of the University of Maryland School of Medicine to the initial development of the Johns Hopkins Hospital and the Johns Hopkins University School of Medicine. Bull Sch Med Univ Md 1957;42(5):86-91.

5. Pittman J. Tinsley Randolph Harrison - The founding editor of Harrison's Principles of Internal Medicine, 2011. Webpage url: http://www.doctorshangout.com/profiles/blogs/tinsley-randolph-harrison-thefounding-editor-harrisons-principle Accessed on Nov 24, 2016

6. Mattingly D. Proceedings of the conference on the postgraduate medical centre. Journal clubs. Postgrad Med J 1966;42(484):120.

7. Linzer M, Mercando A, Hupart $\mathrm{KH}$. Role of a medical journal club in residency training. $J$ Med Educ 1986;61(6):471-3.

8. Lonsdale A, Sietsma Penington J, Rice T, Walker M, Dashnow H. Ten Simple Rules for a Bioinformatics Journal Club. PLoS Comput Biol 2016;12(1):e1004526.

9. Spillane AJ, Crowe PJ. The role of the journal club in surgical training. Aust $N Z J$ Surg 1998;68(4):288-91.

10. Ahmadi N, McKenzie ME, Maclean A, Brown CJ, Mastracci T, McLeod RS. Teaching evidence based medicine to surgery residents-is journal club the best format? A systematic review of the literature. J Surg Educ 2012;69(1):91-100.

11. Shifflette V, Mitchell C, Mangram A, Dunn E. Current approaches to journal club by general surgery programs within the Southwestern surgical congress. J Surg Educ 2012;69(2):162-6. 
12. Corcoran M. Using the MAARIE framework to read the research literature. Am J Occup Ther 2006;60(4):367-8.

13. Gehlbach SH, Bobula JA, Dickinson JC. Teaching residents to read the medical literature. $J$ Med Educ 1980;55(4):362-5.

14. Linzer M, Brown JT, Frazier LM, DeLong ER, Siegel WC. Impact of a medical journal club on house-staff reading habits, knowledge, and critical appraisal skills. A randomized control trial. JAMA 1988;260(17):2537-41.

15. Deenadayalan Y, Grimmer-Somers K, Prior M, Kumar S. How to run an effective journal club: a systematic review. J Eval Clin Pract 2008;14(5):898-911.

16. Honey CP, Baker JA. Exploring the impact of journal clubs: a systematic review. Nurse Educ Today 2011;31(8):825-31.

17. De Broe M. Journal club. Methylation determines fibroblast activation and fibrogenesis in the kidney. Kidney Int 2010;78(5):430.

18. Bowen AC, Connell TG, Bryant PA. Evaluating a web-based paediatric infectious diseases journal club: more than just critical appraisal? BMC Med Educ 2014;14:242.

19. Goldfarb DS, Curhan GC. A new CJASN feature: CJASN's eJournal Club (eJC). Clin J Am Soc Nephrol 2012;7(1):2.

20. Plante TB, Iberri DJ, Coderre EL. Building a Modern Journal Club: The Wiki Journal Club Experience. J Grad Med Educ 2015;7(3):341-3.

21. The Utility of a Real-time Microblogging Service for Journal Club in Allergy and Immunology. Annals Of Allergy Asthma \& Immunology; 2009. Amer Coll Allergy Asthma Immunology 85 West Algonquin Rd Suite 550, Arlington Hts, II 60005 Usa.

22. Reich ES. Researchers tweet technical talk. Nature 2011;474(7352):431.

23. Roberts MJ, Perera M, Lawrentschuk N, Romanic D, Papa N, Bolton D. Globalization of continuing professional development by journal clubs via microblogging: a systematic review. J Med Internet Res 2015;17(4):e103.

24. Symplur Analytics. NephJC Analytics from Symplur Healthcare Hashtags Project. Symplur Healthcare Hashtags Project, 2016. Webpage url: http://www.symplur.com/healthcarehashtags/NephJC/ Accessed on Nov 24, 2016

25. Topf J, Hiremath S. The NephJC Homepage, 2016. Webpage url: http://www.nephjc.com/ Accessed on Nov 24, 2016

26. Participation in the Open, Online, Twitter-Based, Nephrology Journal Club, \#NephJC. American Society of Nephrology; 2015; San Diego. American Society of Nephrology.

27. Thangasamy IA, Leveridge M, Davies BJ, Finelli A, Stork B, Woo HH. International Urology Journal Club via Twitter: 12-month experience. Eur Urol 2014;66(1):112-7.

28. Madariaga H, Hiremath S, Topf J. Nephrology Journal Club's Social Stories, 2016. Webpage url: https://storify.com/NephJC/ accessed on Nov 24, 2016

29. Slavov N. Making the most of peer review. Elife 2015;4.

30. Hiremath S. NephJC: Nephrology Journal Club: National Library of Medicine, 2015. Webpage url: https://www.ncbi.nlm.nih.gov/myncbi/nephjc\%20\%20nephrology.journal\%20club.1/profile Accessed on Nov 24, 2016

31. NCBI Staff. Meet PubMed Commons: The new comments forum in PubMed: National Library of Medicine, 2013. Webpage url: https://pubmedcommonsblog.ncbi.nlm.nih.gov/2013/12/19/meet-pubmed-commons-thenew-comments-forum-in-pubmed/ Accessed on Nov 24, 2016

32. Wikipedia. Journal Club, 2016. Webpage url: https://en.wikipedia.org/wiki/Journal_club accessed on Nov 22, 2016 